\title{
O LUGAR DO SINCRETISMO NAS LINGUAGENS MULTICÓDICAS
}

\section{THE PLACE OF SYNCRETISM IN MULTICODES LANGUAGES}

\author{
Waldir Beividas \\ USP - Universidade de São Paulo
}

\begin{abstract}
RESUMO: O autor apresenta breve revisão crítica do conceito de sincretismo em dois vetores. No primeiro, retoma as formulações que mais se difundiram no campo, a partir das propostas de A. J. Greimas e J. Courtés, no primeiro grande dicionário da teoria (1979), e de J. M. Floch no segundo (1986). No segundo, apresenta breve resumo de suas próprias hipóteses elaboradas em texto de dissertação de mestrado (1983) que permaneceu inédita. Tem a intenção de colocar lado a lado os dois vetores de sua revisão para a reflexão crítica dos interessados no tema. $\mathrm{O}$ autor considera que ainda hoje não se tem uma definição adequada desse conceito, nem do lugar preciso de sua ocorrência nas instâncias criadas em teoria, quando acionado para a descrição das linguagens multicódicas. A extensão do conceito de sincretismo, de seu campo de origem na linguística fonológica e morfossintática (como "neutralização") para o vasto campo das linguagens complexas, embora já prenunciado nas proposições hjemslevianas, requer uma transposição de grande envergadura, ainda não contemplada pelos desenvolvimentos que o conceito já pôde obter. Endossa algumas tarefas urgentes, propostas por J. L. Fiorin (2009), para superar a carência e propor outras.
\end{abstract}

PALAVRAS-CHAVE: Semiótica; Sincretismo; Neutralização; Superposição; Fusão; constelação.

ABSTRACT: The author of this study presents a brief two-part critical review of the concept of syncretism. In the first part, it is incorporated the formulations that had been more disseminated in the Semiotics field, especially the proposals of Greimas and Courtes in the first great dictionary of theory (1979) and the proposal of J. M. Flochs in the second dictionary (1986). In the second part, a summary is presented concerning the author's hypotheses which were developed in his master's dissertation (1983). The objective is to put side by side the two critical parts of his text to make a revision and submit it to the reflection of those interested in the subject. The author believes that even today there is not either an adequate definition of the concept of syncretism or a precise place of its occurrence in the theoretical instances when it is required the description of multi-code languages. The extension of the concept of syncretism - from its field of origin in phonological linguistic and morphological and syntactic analysis (such as "neutralization") to the vast field of complex languages - although already foreshadowed in Hjelmlev's propositions, requires a transposition of large-scale that is not yet considered in the developments that the concept has already achieved. The author endorses some urgent tasks proposed by Fiorin (2009) to overcome the pointed shortage and proposes others.

KEYWORDS: Semiotics; Syncretism; Neutralization; Overlap; Merger; Constellation. 
[...] mais il est souvent plus aisé de découvrir une vérité que de lui assigner la place qui lui revient

Saussure (1972, p. 100).

\section{Introdução}

Saussure emite a proposição acima quando pensa o princípio do arbitrário do signo linguístico. É bem o que parece ocorrer também quando temos de refletir sobre o estatuto do conceito de sincretismo no interior das pesquisas semióticas e de tentar localizar o lugar que lhe cabe no corpo de conceitos da teoria bem como na tarefa descritiva. Isto porque, diferentemente da análise de um objeto razoavelmente homogêneo como um texto literário objeto já clássico dentro do campo semiótico -, o sincretismo intervém quando os objetos em análise se manifestam simultaneamente por meio de diferentes planos de expressão (sonoros, visuais, gestuais), sensorialidade múltipla que nos induz a chamá-los linguagens sincréticas ou semióticas sincréticas.

Essas nomeações dadas aos objetos em sincretismo são usuais. No entanto, é nosso entendimento, a ser melhor justificado na sequência, que, no âmbito dos estudos semióticos das linguagens sincréticas, ainda não podemos dar por inteiramente satisfatórias as várias tentativas de definição e acionamento do conceito de sincretismo nas numerosas análises feitas ao longo de todo o trajeto em que a teoria semiótica se liberou da linguagem verbal propriamente dita, alargou o horizonte e galgou o campo das linguagens não verbais. Por óbvio, a observação não quer impugnar demérito a ninguém, apenas ressaltar o grau de dificuldade na elaboração de uma boa conceptualização do sincretismo e de seu lugar de operação na descrição dos textos manifestados por meio de múltiplos planos de expressão. ${ }^{1}$

Observada a coisa no tempo, lá se vão boas décadas desde as proposições de Greimas e Courtés sobre o sincretismo no Dictionnaire (1979). Situar neste o início das coisas, como faremos aqui, não significa desconsiderar as proposições de Hjelmslev, nos Prolégomènes (1943). Como estamos diretamente interessados nas linguagens pluricódicas, a datação é escolhida apenas porque as pesquisas que se envolveram com tais linguagem pouco ou nada utilizaram integralmente o conceito hjelmsleviano - mais adstrito aos aspectos da neutralização, mormente fonológica e morfossintática - pautando-se mesmo, na maior parte dos casos, na redefinição sugerida pelos dicionaristas. ${ }^{2}$

Diante disso, este artigo tem duplo intuito: (i) trazer para as discussões atuais sobre o conceito nossa própria leitura do modo como ele se situa hoje, isto é, retomar brevemente e repassar criticamente as soluções mais amplamente difundidas, não nas

\footnotetext{
1 Aos termos postos acima - semióticas sincréticas, linguagens sincréticas - somam-se outros: objetos sincréticos, textos sincréticos, enunciação sincrética, plano de expressão sincrético, processos sincréticos de significação, discursos sincréticos, comunicação sincrética, expressões co-ocorrentes, colhidas aqui e ali na literatura do campo. Como se vê, elas se espalham em diferentes instâncias e níveis do percurso gerativo, a indicar uma polivalência um tanto suspeita das abrangências e, ao mesmo tempo, algum incômodo teórico frente ao princípios de rigor definitório a que a Semiótica sempre procura submeter-se, tudo a dar razão ao Saussure da epígrafe.

${ }^{2} \mathrm{Na}$ verdade das coisas, o conceito de sincretismo, que Hjelmslev demonstrou mais pormenorizadamente nos níveis fonológico e morfossintático, esteve destinado a um uso muito mais generalizante pelo próprio linguista de Copenhague, até mesmo para "fatos que se tem o hábito de considerar como não sendo linguísticos" (1968, p. 118). Legitimado, portanto, também para níveis superiores de análise frasal, transfasal, textual, como bem nota Fiorin (2009, p. 30), no entanto, a semiótica greimasiana, a nosso ver, não tirou dele todos os ingredientes e desdobramentos para a montagem conceptual que gerenciou a proposição do percurso gerativo.
}

Disponível em: http://seer.fclar.unesp.br/casa 
minúcias descritivas caso a caso, mas nos aspectos globais das proposições conceptuais de sincretismo que figuram como base das estratégias de descrição aqui e acolá. A esse momento do artigo chamaremos "o sincretismo: de Hjelmslev a nossos dias"; (ii) apresentar sinteticamente as nossas próprias formulações para o conceito, desenvolvidas em antiga dissertação de mestrado (1983), cujo longo tempo de ineditismo não a disponibilizou para as necessárias apreciações críticas e/ou usos operativos de análise.

\section{O sincretismo: de Hjelmslev a nossos dias.}

Para economia da retomada crítica, não repassaremos aqui as proposições detalhadas de L. Hjelmslev sobre sincretismo, conceito tomado por ele da gramática tradicional de seu tempo e que a fonologia posterior assimilou e difundiu por meio do conceito de neutralização, tradução escolhida para o termo Aufhebung, de Trubetzkoy (cf. CÂMARA JR., 1970: 33). O artigo de J. L. Fiorin - "Para uma definição das linguagens sincréticas" (2009) - apresenta o capítulo 18 dos Prolégomènes, em que Hjelmslev trata do sincretismo, bem como o cotejo das definições com outros capítulos, de forma detalhada, minuciosamente refletida, e com o estimável benefício das exemplificações buscadas em nossa língua, quando os casos se aplicam. Esse artigo, que abre o livro de maior amplitude sobre o tema do sincretismo até hoje surgido em todo o mundo semiótico (OLIVEIRA; TEIXEIRA, 2009), estará aqui sendo o contraponto direto de nossa retomada.

\subsection{O sincretismo no Dictionnaire}

Autores do Dictionnaire, A. J. Greimas e J. Courtés (1979) propõem dupla definição: em seu aspecto mais restrito, consideram o sincretismo como a superposição de dois ou vários termos, duas ou mais grandezas, duas ou mais categorias heterogêneas, recobertas por uma grandeza que as reúne. Tudo parece indicar à primeira vista que superposição, grandezas, categorias, provenham todos diretamente de Hjelmslev. O exemplo dado é o da subsunção de dois funtivos narrativos (dois actantes) por um único discursivo (um ator): nos programas narrativos de aquisição, os actantes sujeito do fazer (responsável pela operação) e sujeito de estado (beneficiário da conjunção) são subsumidos pelo mesmo ator, portanto sincretizados nele. Para este caso, os dicionaristas propõem caracterizá-lo, ainda, como sincretismo a posteriori, tendo em vista que o lugar dele se deu numa instância acima, mais superficial (atorial), do que dos funtivos de partida (actanciais) do percurso gerativo da significação. A proposta visa diferenciá-lo de um sincretismo a priori que caracterizaria de saída, por exemplo, a instância da enunciação de todo o discurso, lugar de um sincretismo subsumindo o eu-aqui-agora. Fiorin (2009, p. 32) amplia esse entendimento para demais casos em que o sincretismo ocorra "no mesmo nível em que estão os funtivos em superposição". A boa ilustração: "Campinas está a quantos quilômetros de São Paulo? Resposta: a uma hora » (tempo e espaço sincretizados, de mesmo nível).

O exemplo do sincretismo a posteriori, à primeira vista, dá-nos a entender que nessa definição "restrita", os autores do dicionário acompanhariam diretamente as proposições de Hjelmslev. Sem pretender levar mais adiante a discussão neste ponto preciso, teríamos de averiguar melhor o caso ilustrado pelo Dictionaire porque ele localiza o terceiro funtivo que vai manifestar o sincretismo (o ator) num nível outro, acima, do que o dos funtivos de partida, sendo que em Hjelmslev o manifestante é via de regra um dos dois funtivos, de mesmo nível, que entram em superposição ou suspensão (note-se o arquifonema I em final de sílaba átona- bebe, come, bate, ...- ou o caso neutro do latim - templum 
nominativo e acusativo sincretizados). O conceito de superposição em Hjelmslev tem definição bem enquadrada: trata-se de uma "mutação suspensa" (1968, p. 113, 116) - no caso acima do "e" e do "i" que são via de regra invariantes na nossa língua - isto é, trata-se de mutação neutralizada em algumas ocorrências de sílabas átonas. A diferença entre os dois funtivos (no caso, fonemas) se anula, e tanto um como o outro pode ser realizados, nesse contexto fonológico, sem causar nenhuma diferença de conteúdo. Tanto um como o outro significa: ou um ou outro, indiferentemente. A bem dizer, a realização concreta do fonema nessa posição pode também ser foneticamente intermediária entre o "e" e "i": os dois podem perder um pouco seu normal ponto de articulação em benefício de uma terceira realização (I). Trata-se do caso de "fusão", segundo Hjelmslev, em que a manifestação do sincretismo é idêntica à manifestação de nem um nem o outro dos dois funtivos que entram nele, mas um terceiro. Note-se, todavia, que não extrapolamos o mesmo nível (fonológico).

Ora, não nos parece que tal conceito de superposição possa ser aplicado, em condições de estrita igualdade, no caso da subsunção actancial sujeito do fazer e sujeito de estado pelo único ator. Aqui trata-se de uma superposição por cumulação (execução da ação + benefício resultante) e também subida de nível; lá trata-se de suspensão, alternação ou fusão no mesmo nível. Noutros termos, pensamos que começa já aqui um desvio, alargamento e, por assim dizer, 'afrouxamento', pelos autores do dicionário, do conceito minuciosamente especificado em Hjelmslev, nome ausente do verbete, talvez signo de uma espécie de alforria, no caso do conceito de superposição e, portanto, de sincretismo.

Por sua vez, o sincretismo a priori para cuja ilustração é tomada a instância da enunciação, como sincretização do tempo, espaço e deitização de todo o discurso, terá posteriormente em J. M. Floch um desdobramento e centralidade que merecerão comentários à parte, conforme veremos adiante.

Mais acentuadamente, o afrouxamento se dá na segunda definição do Dictionnaire: em menos de cinco linhas ficam caracterizadas como semióticas sincréticas aquelas que acionam várias linguagens de manifestação. É dado o exemplo da ópera, do cinema, como igualmente o da comunicação verbal acompanhada de "elementos paralinguísticos (gestos, proxêmica) e sociolinguísticos", com o arremate da curta frase acompanhado por um "etc.". Qualificada de "totalmente imprecisa" por alguns semioticistas (FIORIN, 2009, p. 33) e, por isso, geradora de equívocos, queremos ver antes nessa segunda proposta - bem lacônica, é verdade, mas de sentido "mais amplo", como o sugere o verbete do dicionário - menos uma definição propriamente dita e mais uma caracterização eclética do campo a ser desbravado: as multilinguagens operando concomitantemente, ainda sem se saber direito como. Estavam apenas jogados os dados...

\subsection{O sincretismo, segundo Floch.}

Jean-Marie Floch foi o semioticista do grupo greimasiano que esteve desde inícios dos anos 1980 à frente dos ateliês de pesquisa sobre a questão do sincretismo. A partir de então, suas proposições foram as que mais repercutiram nas análises vindouras e influíram nos entendimentos do conceito. Redigiu os quatro parágrafos do verbete syncrétiques (sémiotiques) do Dictionnaire II assinado por Greimas e Courtés (1986). Como outros (cf. FIORIN, 2009), também entendemos que Floch procurou precisar melhor o conceito, com o 
intuito de mantê-lo diretamente subordinado às proposições de Hjemlslev, frente a outras tentativas que então se faziam, provenientes de outras escolas semiológicas lato sensu. ${ }^{3}$

Em nosso entendimento, a iniciativa, louvável, não cumpriu o objetivo almejado de melhor precisão: os quatro parágrafos, na verdade bem heterogêneos no teor, conforme veremos a seguir, acabaram por lançar o conceito de sincretismo numa encruzilhada de caminhos de interpretação e de operação que, salvo melhor juízo de análises empíricas, não resolveram as "imprecisões" das proposições do Dictionnaire I, não limparam melhor o terreno. É por isso que, ainda em nosso entendimento, a maioria dos trabalhos empíricos posteriores, cuidam bem de inserir em suas aberturas algumas definições citatórias desse verbete, mas não é fácil ver no que elas induzem as operações analíticas propriamente ditas que as seguem. Nesse caso, temos de admitir não a inabilidade geral das análises, mas as dificuldades que ainda remanescem quanto às definições de Floch e dos dicionaristas, e quanto à operacionalidade do conceito de sincretismo derivado dessas definições.

Revendo os quatro curtos parágrafos do verbete do Dictionnaire II (1986), é de se notar que eles retomam, com algumas inserções e outras supressões, um artigo também curto do mesmo Floch, "Estratégias de comunicação sincrética", escrito alguns anos antes (1983), nas publicações do Bulletin da equipe greimasiana, número intitulado "Sémiotiques syncrétiques", dirigido por ele próprio, contendo, além do seu, cinco breves textos de outros autores. $^{4}$

Para o que mais interessa em nossa retomada crítica, convém selecionar e comentar os pontos centrais dos quatro parágrafos do verbete. No primeiro deles, Floch caracteriza como semióticas sincréticas o acionamento (mise en ceuvre) de várias linguagens de manifestação. Preferimos a tradução acionamento para ressaltar o sema (ação) fortemente presente na expressão francesa, ao invés dos termos aplicação ou emprego, usados aqui e acolá. Essa definição repete o contido na segunda definição, mais ampla do sincretismo, pelo Dictionnaire I, conforme vimos acima. Mas a complementa, lembrando a dificuldade de se trabalhar sem uma tipologia convincente dessas linguagens num acionamento sincrético delas. Anunciada a dificuldade desde então, ela persiste até hoje. Não conseguimos desenvolver uma tal tipologia para as linguagens ou semióticas sincréticas, em grande parte, justamente porque, a nosso ver, os parágrafos seguintes deslocaram o foco da questão do sincretismo das linguagens, e de seu modo de síncrese, para outras paragens, outras instâncias ou planos do percurso gerativo.

Com efeito, já no segundo parágrafo do verbete, o sincretismo é deslocado para o plano de expressão dessas linguagens e, mais restritivamente, para a substância de seus planos de expressão, uma vez que seus elementos advém “de várias semióticas heterogêneas". Observe-se, porém, que esse deslocamento do sincretismo para o plano da expressão é o segundo tempo de um primeiro, que exige previamente o foco de análise no plano do conteúdo para garantir "um todo de significação". Aqui, certamente Floch acompanha de perto o Greimas de Sémantique structurale quando este pleiteia a independência da

\footnotetext{
${ }^{3}$ Floch não menciona nominalmente as outras orientações, apenas aponta tendências de estudos sígnicos que introduziam o "referente" nas suas análises, estudos incidentes na substância dos significantes envolvidos nas linguagens complexas ou nos canais sensoriais de sua transmissão.

4 Por economia, não comentaremos os demais artigos desse número, os quais pouco ou nada discutem efetivamente o sincretismo como questão. Vale registrar apenas a conclusão de uma entrevista de Floch com Marie-Claire Ropars-Wuilleumier, autora do livro Le texte divisé: essai sur l'écriture filmique (Paris: PUF, 1981), na qual, de forma drástica - a nos desafiar cabalmente - a entrevistada torna nula (infirmée) a hipótese de um sincretismo das linguagens, perante o que considera a "impossibilidade de delimitar unidades que funcionariam separadamente em cada linguagem e que permitiriam organizar cada cadeia material em um sistema significante autossuficiente (se suffisant à lui-même)" (in FLOCH, 1983, p. 25).
}

Disponível em: http://seer.fclar.unesp.br/casa 
significação perante a natureza do significante pelo qual ela se manifesta. Mesmo nas linguagens que envolvem significantes de natureza sensorial diversa, dizia Greimas, "as significações que estão aí eventualmente contidas são simplesmente humanas" (1966, p. 11). Somente depois de garantida a análise do conteúdo, segundo o novo parágrafo de Floch, é que se poderá retornar à manifestação para compreender a "distribuição" do conteúdo nas várias linguagens e, com isso, abordar finalmente seus planos da expressão. Reconhece à época a fragilidade de meios para essa nova incursão, dada a ausência de metalinguagem descritiva para este plano, frente à pujança metalinguística que já se aplicava ao plano do conteúdo.

Ora, a crítica que somos impelidos a introduzir perante este segundo parágrafo é tríplice: (i) o "todo de significação" pleiteado, fica dado a priori, petição de princípio, dá na partida aquilo que deveria ser demonstrado na chegada, como resultante das articulaões sincréticas. O sincretismo no plano do conteúdo fica sendo um salto mágico, uma simbiose um tanto misteriosa, que não demonstra de que maneira as formas do conteúdo (e suas substâncias) das linguagens envolvidas entram em dependência - conceito maior de Hjelmslev a definir toda semiótica - umas perante outras, e a natureza das dependências entre elas; (ii) propor um retorno à manifestação, somente depois da análise do conteúdo, para verificar "as regras da sua distribuição" (ênfase nossa) entre as linguagens, implica dizer que estas, nas especificidades de tratamento de suas gramáticas de manifestação, não criam nada de novo de conteúdo, de efeitos de sentido singulares, apenas veiculam algo dado de antemão no plano superior. A evidência parece depor contra isso; (iii) por fim, propor que as semióticas sincréticas constituem seu plano da expressão, com o adendo de que isso se dá "mais precisamente" nas suas substâncias de expressão advindas de semióticas heterogêneas, significa a nosso ver desconsiderar o sincretismo das respectivas formas da expressão. Frente à teoria hjelmsleviana, segundo a qual a forma determina a substância, a proposição de Floch inverteria a equação: substâncias (sincretizadas) determinariam a (nova) forma resultante. Problema teórico com decorrências talvez pesadas demais, que mereceria discussões refletidas, ao que parece, ainda não tidas posteriormente.

O terceiro parágrafo entra em novo terreno para situar o sincretismo. Anunciado ao final do parágrafo anterior, o núcleo da questão se aloca em nova instância, no que Floch identifica como enunciação sincrética. Aqui a investigação aponta duplo vetor, misturadamente: (i) dos "procedimentos de sincretização", isto é, do "processo gerativo do sincretismo"; (ii) das "estratégias sincréticas" envolvidas na comunicação. Eles vêm exigidos pela recusa de considerar válida qualquer hipótese de várias enunciações concorrentes nas linguagens sincréticas, uma para cada linguagem envolvida. A seu ver, a pluralidade de linguagens é recurso de "estratégia, global, de comunicação sincrética" que vai "gerar" um texto sincrético integralmente administrado pela competência de apenas "um único enunciador". O parágrafo avança procurando circunscrever a pluralidade aí envolvida, propondo uma definição, que considera "menos intuitiva", para as semióticas sincréticas, identificando-as como uma "pluralidade de substâncias para uma forma única".

Como pode ser visto, o autor atravessa em livre trânsito por duas instâncias ou planos sem problematizar mais adequadamente, a nosso ver, a legitimidade desse trânsito. Afinal, o sincretismo é uma estratégia enunciativa global que se serve de linguagens várias, contraindo suas funções, pois, no plano do conteúdo, nas formas do conteúdo, assim sincretizadas, ou o sincretismo será a resultante da forma única gerada pelo sincretismo da pluralidade das substâncias, tudo se dando no plano da expressão? A mistura de planos aqui, sem melhor teorização disso, não torna o conceito e sua operação mais claros, salvo melhor juízo. Além disso, do ponto de vista da teoria hjelmsleviana, se a forma determina a substância, qual substância vai resultar, no final do sincretismo, determinada por 
essa pretendida "forma única"? Bem diferentemente da "fusão" em arquifonema (I) dos casos de sincretismo por suspensão dos fonemas (e, i) em que a resultante é nova forma (e substância), no presente caso tudo se torna mais complexo. Perante a enorme variedade das substâncias da expressão envolvidas, - por exemplo no caso da linguagem chamada cinematográfica (a oralidade da fala, a sonoridade da música, cores, luzes e sombras do visual, movimentos das gestualidades, a espacialidade e deslocamentos verticais, horizontais e oblíquos dele nas angulações de uma câmera cinematográfica) - é difícil imaginar uma substância resultante dessa forma única. No caso fonológico, tudo se resolve num nível homogêneo de forma e substância. Aqui não. Por isso, subscrevemos inteiramente apreciações análogas de Fiorin que culminam no entendimento de que tal forma única seja "teoricamente insustentável" (2009, p. 36-37). ${ }^{5}$

Por sua vez, depositar o encargo do sincretismo, por assim dizer, nas costas do sujeito da enunciação não vai sem o risco da generalização excessiva: afinal, tudo é comandado pela instância da enunciação. O conceito de sincretismo se esvai, perde sua especialidade e a operação corre o risco de não ir além de uma simbiose misteriosa. Para dizêlo de modo anedótico, a enunciação não é operadora do sincretismo; ela é, antes, sua primeira vítima: acionar semióticas ou pluralidade de semióticas que se manifestem por canais sensoriais variados obriga a enunciação - seja ela de actante único ou coletivo - a curvar-se e ajustar-se às coerções que as substâncias heterogêneas (com as respectivas formas gramaticais de sua expressão) introduzem em síncrese. Se a enunciação deve ser vista sempre como uma instância pressuposta, no controle do processo sintagmático do discurso, ela própria tem de pressupor o sistema de possibilidades e coerções paradigmáticas, portando, os sistemas linguageiros que vão entrar em sincretismo.

Por fim o parágrafo quarto do verbete, assim como a última parte do terceiro, apenas introduzem não mais qualquer deliberação sobre o conceito ou seu lugar de operação, mas sim a que serviriam as análises das semióticas sincréticas: (i) teriam um cunho sociossemiótico ao investigar as "atitudes que uma sociedade adota frente às suas linguagens e seus signos"; (ii) contribuiriam para a construção de uma teoria semiótica dos atos, haja vista o maior poder manipulatório que possam ter as comunicações sincréticas.

Tudo posto numa balança, temos de elogiar o esforço definitório. Alguns dados foram lançados, é certo, mas temos igualmente de reconhecer que os resultados foram parcos, os lugares do sincretismo saíram alargados, desfocados no alvo, com níveis de operação misturados, enfim deixando às nossas reflexões atuais e futuras o encargo de melhor definir o conceito.

\subsection{O sincretismo segundo Beividas.}

Se fôssemos observar a estrita cronologia, este item deveria preceder o anterior. Em dissertação concluída em meados de 1983, intitulada "Semióticas sincréticas (o cinema). Posições" propusemos uma série de hipóteses que o ineditismo do texto por longo tempo não possibilitou que circulassem nos debates. ${ }^{6}$

\footnotetext{
5 O entendimento acima já o tínhamos desde a época em que surgiu o artigo de Floch no Bulletin e posteriormente o verbete por ele redigido no Dictionnaire II. A bem da memória, foram essas formulações, diametralmente diferentes das propostas trabalhados em dissertação de mestrado (BEIVIDAS, 1983), concluída anteriormente aos textos de Floch aqui sob exame, que inibiram o empenho em sua publicação à época (cf. adiante).

${ }^{6}$ Nem mesmo um curto artigo, publicado alguns anos depois, ajudou muito nas discussões. Numa revista quase artesanal, de minúscula circulação, o artigo visou apresentar resumidamente alguns tópicos do texto maior, Disponível em: http://seer.fclar.unesp.br/casa
} 
Considerado o contexto teórico das pesquisas semióticas dos inícios dos anos 1980, esse texto se engajou integralmente em enfrentar a questão das semióticas sincréticas, o cinema pairando como pano de fundo referencial e alvo final. Depois de posicionar o ponto de vista da semiótica greimasiana perante os trabalhos da crítica cinematográfica, da semiologia sígnica e das análises psicanalíticas do cinema, então em cena (1983, p. 18-46), o trabalho visou a propor um modelo que pudesse explicar o modo de imbricação e compatibilização (de sincretismo) dos vários códigos operantes numa linguagem complexa como a do cinema, em dois eixos: o modo de presença (paradigmática) simultânea dos códigos envolvidos e seu modo de funcionamento (encadeamento sintagmático).

Adotando a perspectiva dos níveis de articulação da significação do percurso gerativo, foi lançada a hipótese de que o lugar de acontecimento do sincretismo das linguagens complexas seria o nível da manifestação (nível correspondente ao que Greimas propunha como nível de textualização, para o caso da linguagem verbal). Houve na hipótese o cuidado de entender esse nível como "estrutura de manifestação" e, portanto, como estrutura, imanente (apesar do paradoxo aparente). A hipótese pareceu legítima: a semiótica advoga aquém das várias gramáticas de manifestação o imperativo de uma gramática (narratológica) dos conteúdos, eminentemente como a "forma semiótica" do sentido - le sens du sens (GREIMAS, 1970, p. 16) -, forma comum a todas as linguagens. De modo que as particularidades específicas, as especiarias diversas de resolução desse sentido nas linguagens complexas, só poderiam ser extraídas quando, postas entreparênteses (operacionalmente) as articulações dos níveis mais profundos, a atenção fosse focada e centrada nas articulações mais próximas à manifestação, fosse observada mais de perto a entrada do plano da expressão no jogo da significação.

Essa hipótese pede maior comentário. Parte do entendimento de que sob o fundo de dificuldade que o conceito de estrutura de manifestação apresenta, parece consensual entre os semioticistas entender a manifestação como a instância que presentifica a forma na substância (segundo o modelo hjelmsleviano). É o lugar onde um texto toma sua concretude material, por assim dizer. Cabe dizê-la instância final, ad quem, do engendramento da significação. Atingida essa instância, nada mais haveria a fazer em semiótica, pois aí, de certo modo, acaba toda tarefa modelizante. Nessa perspectiva, a instância de manifestação, conquanto seja a própria realidade e suporte material da existência da significação, ela mesma não tem em si o que Hjelmslev concebia como "existência científica" (1968, p. 99). Apenas o têm as instâncias anteriores, porque formalizadas. A manifestação aparece como o estado que o grande linguista concebia como "matéria amorfa": uma nebulosa de cores, de sons, de brilhos e de figuras (no caso de uma manifestação em cinema). Qualquer captação ou decifração significante só se dá porque ultrapassa essa materialidade pelo ato da semiose, isto é, pela "função semiótica", conjunção de formas (do conteúdo e da expressão) e não de substâncias, situada, portanto, em instância logicamente anterior ao exato limiar da manifestação propriamente dita. Noutros termos, também a instância da manifestação, como objeto a descrever, é ela própria um dado prévio à manifestação. É por decorrência desses ensinamentos de Hjelmslev que a hipótese da estrutura de manifestação deixa entender que qualquer teoria semiótica, que opere com existentes científicos, só pode se dar como um trabalho de formas estruturais em imanência, e jamais na manifestação concreta.

Assim, a estrutura de manifestação se desenharia como um conjunto de articulações o mais próximo, por assim dizer, do ato de semiose, da função semiótica, solidariedade entre conteúdo e expressão. A entrada da expressão introduz portanto as

(1987: 13-21). O que, pensamos, autoriza-nos aqui sua retomada, para contraste, com as proposições comentadas acima. 
coerções da matéria desse plano, substantificada pela forma da expressão. Exemplos simples: a linearização do texto linguístico, coerção material do tempo de fonação, a globalização de um texto pictórico, coerção material do espaço de seu enquadramento, a simultaneidade dos dois num filme moderno (não mudo).

De modo que o lugar a acontecer o sincretismo, hipotecado na instância de manifestação, fez com que a ideia de uma semiose sincrética decorresse imediatamente disso. O desafio, então, era entender como definir tal semiose sincrética envolvendo vários códigos de matéria significante distinta. Para isso, o primeiro passo foi o de centrar a atenção no plano da expressão das linguagens (dando operacionalmente por pacífico o percurso gerativo da significação montado pela semiótica para o plano do conteúdo). Imaginar no plano da expressão um paralelismo apressado com o percurso gerativo dado ao conteúdo, em níveis de profundidade, ao modo de um isomorfismo pari passu, pareceu então idéia pouco viável perante uma outra sugestão que pôde ser destilada de um texto de Greimas em seu Du sens: "La structure sémantique" (1970, p. 39-48). Texto curto e difícil de interpretação, a nossa foi a de que Greimas estaria concebendo o conceito de "forma" de um modo tríplice de pertinência e de profundidade: as linguagens teriam uma forma semiótica (do conteúdo e da expressão), autônoma e anterior à forma linguística (do conteúdo e da expressão), porém uma terceira, forma científica, lhes seria logicamente anterior. Ele próprio confessava a aparência de "complicação inútil" disso (p. 43), mas via na proposição boa maneira de "situar a estrutura semântica na economia geral de uma teoria epistemológica geral", melhor ainda, de "definir as ciências como linguagens construídas..." (p. 45). Para ilustrar, foi utilizado o exemplo da cadeia sintagmática de uma forma científica, a fórmula química $\left(\mathrm{H}_{2} \mathrm{O}\right)$, que se deixa captar como percepção (gustativa, olfativa) enquanto forma semiótica (líquido inodoro, vital, saúde, higiene...), a disputar valores e posições actanciais diversas no percurso, resolvidas linguisticamente numa estrutura morfemática (água). Pareceu legítimo estender e generalizar a proposição greimasiana para outras linguagens além da verbal, de modo a entendê-las todas elas possuindo, além da forma científica e da forma semiótica uma forma códica no seu nível de manifestação.

Aplicado o modelo tríplice à linguagem do cinema a ideia foi a de imaginar a descrição da forma científica - ao modo como a fonética traz suas descrições físico-acústicoarticulatória na produção dos fones - como extraída da descrição física da projeção em tela, das propriedades físicas e técnicas da criação das imagens através dos aparelhos tecnológicos, das coerções retinianas de captação das imagens (cf. as discussões sobre número de fotogramas para uma percepção, sobre o fotograma como "a menor unidade" cinematográfica). No nível da forma semiótica foram propostas uma semiótica proxêmica (a cuidar das significações dos movimentos internos (diegéticos) dos personagens, uma semiótica cinética (de KINETIKOS $\approx$ que põe em movimento) para os movimentos externos da câmara na linha horizontal (travellings), no eixo vertical (angulações, plongés, contreplongés), uma semiótica focal (closes e enquadramentos). Foram propostas apenas sugestivas, lembrando que angulações, travellings, flash back, plongés e tantos outros procedimentos cinematográficos poderiam postar-se como a forma códica, isto é, como a resolução "textual" de um filme. Noutros termos, as formas códicas, acima mencionadas, representariam o enquadramento, ou resolução, das formas semióticas (proxêmica, focal, cinética) numa gramática (códica) de manifestação. Por meio das formas códicas, as formas semióticas se veriam conformadas a uma gramática de manifestação (BEIVIDAS, 1983: 86-88).

Montado em forma tríplice, tal como ilustrado acima, o plano da expressão não constituiria um "percurso gerativo" da significação. Embora de toda evidência o acionamento dessas especiarias códicas do cinema pareça provocar efeitos de sentido singulares, 
impossíveis de outras maneiras, havia um impedimento incômodo, perante o que dizia Greimas (1970, p. 8-9), conquanto referindo-se localmente ao linguístico: o significante é apenas uma "cobertura sonora ou gráfica que, embora nada tendo a ver com o sentido o deixa filtrar e chegar até nós" (ênfase nossa). Assim entendido, o plano da expressão não poderia, efetivamente, ensinar nada sobre o sentido. Torna-se para a semiótica apenas um lugar de verificação. Sua análise visaria estabelecer apenas uma espécie de teste de controle entre os dois planos, medida de garantia da coerência descritiva da significação, empreendida eminentemente no plano do conteúdo. $\mathrm{O}$ plano da expressão responderia por articulações simplesmente discriminatórias, portadoras tão somente de 'sentido negativo' (a possibilidade de dizer que « $\mathrm{p}$ » não é « $\mathrm{b} »-$ digamos, em cinema: um plongée não é um contre-plongée). Assim limitada, sua função é a de controle ao que se vai postular e descrever no plano do conteúdo: à menor alteração de sentido no plano do conteúdo deve corresponder alguma alteração no outro, e vice-versa.

$\mathrm{O}$ entendimento nosso à época não assimilou integralmente a restrição greimasiana imposta ao plano da expressão. Mesmo porque, ela passou a rivalizar com sugestão oposta, de seu discípulo Floch (1978, p. 13), para quem também o significante era possível considerá-lo como algo mais do que um número de categorias discriminatórias. $\mathrm{O}$ significante poderíamos apreendê-lo, dizia Floch, "como um significado e nos interessarmos pela organização lógico-semântica da 'forma', pelo sentido investido nas categorias". Com efeito, para um exemplo breve, basta que tomemos um simples dito como, por exemplo, este que trouxemos à época, de memória, de uma canção de Itamar Assunção: "entre um sim e um não existe um vão". Ou seja, a rima /não-vão/ é a única a dar valor mais intenso de 'verdade' e um efeito de sentido poético do que outras alternativas (desesperadas): entre um sim e um não há...espaços, intervalos, distância, hesitação, separação, um mundo de coisas, ou outras soluções que o valham. A rima é, pois, eminentemente uma forma semiótica cujo efeito de sentido é derivado imediatamente do plano da expressão, que colabora, pois, com seu semantismo de expressão, específico, para o jogo final dos efeitos de sentido de uma frase dessas. Isso, ao que nos pareceu, abre um imenso canteiro de trabalho para as análises descritivas do plano da expressão das outras linguagens. Nenhuma fonética, nenhuma fonologia, salvo melhor juízo, consegue explicar o núcleo forte, semiótico, de uma rima. Noutros termos, a rima reverbera, alitera, provoca, excita - termos que foram propostos à ocasião como tateamentos, à espera de definição mais justa e adequada - cria, enfim, um reforço do efeito de sentido «verdade », de eficácia, para o que se está a significar no plano do conteúdo.

Diante desse entendimento, se era demasiado arriscado conceber o plano da expressão como gerador integral e sui generis da significação propriamente dita, propusemos um meio termo ao preferir a hipótese de que o plano da expressão responderia por um percurso de consignação, revitalizada a etimologia do termo: marcar com um sinal, selar (a significação do plano do conteúdo), ao mesmo tempo que preservada a intersecção sêmica com o termo significação. Assim, o plano da expressão não cria, mas é o único a consignar a significação do plano do conteúdo. A expressão consignaria a montagem da significação cujo encargo descritivo caberia à análise do plano do conteúdo.

Encontrada essa opção que pareceu satisfatória para modelizar o plano da expressão, faltava propor uma solução teórica para a semiose sincrética, isto é, a da imbricação dos vários códicos co-ocorrentes nas linguagens complexas (como a do cinema). Para isso, foi retomado de Hjelmslev o conceito de "função", entre seus "funtivos", e a legitimidade por ele conferida à possibilidade de haver função entre funções (1968, p. 49). Assim, partimos do mais básico e geral: uma semiótica - uma linguagem, um código - se 
define pela função semiótica entre seus planos (funtivos), função de solidariedade, isto é, de pressuposição recíproca. Se assim é, sua presença, sua operação, fica circunscrita apenas e tão somente no interior de uma linguagem, de um código. Ou seja, é uma função eminentemente intrínseca de cada linguagem, de cada código, portanto intrassemiótica (e intracódica).

A função (intra-)semiótica, função de interdepependência, segundo Hjelmslev, embora seja apenas um dos três tipos de funções formulados pelo linguista de Copenhague (ao lado da função de determinação e função de constelação), foi a única que se difundiu amplamente em semiótica, a ponto de quase forçar o raciocínio a operar apenas com base na interdependência, na pressuposição recíproca. Mas foi com base na abertura teórica permitida pelos outros tipos de função - principalmente a função de constelação - que pudemos postular que as significações (funções semióticas) dos códigos, que operam concomitantemente numa linguagem complexa, não são estanques, cada código estabelecendo sua função intrassemiótica por si e detendo-se aí. As funções semióticas, internas aos códigos, não operam isoladamente, cada uma formando uma significação particular, para depois se juntarem por algum processo estranho de somatória ou, mais misterioso, de simbiose - coisas difíceis de serem integradas na economia da teoria semiótica. A sua integração só poderia ser explicada satisfatoriamente, vendo aí que novas funções fossem contraídas entre as funções semióticas de cada código. Afinal, segundo Hjelmslev, analisar é eminentemente registrar funções.

Posto isto, foi proposto que a co-ocorrência de dois ou mais códigos numa linguagem complexa poderia ser explicada com a hipótese de uma função "intersemiótica(s)", ou "função de sincretização" entre as respectivas funções semióticas. A função de sincretização teria o estatuto de constelação, nos termos de hjelmslev, porquanto os funtivos figuram nela como variáveis, isto é, cuja presença não é condição necessária para a presença de outro ou dos outros. Ou seja, não haveria pressuposição recíproca entre os códigos operantes nessa linguagem complexa, apenas uma implicação recíproca: se se verifica a presença de duas ou mais funções semióticas (dois ou mais códigos) num texto (fílmico, por exemplo), elas passam a implicar-se mutuamente, a entrar em sincretismo. Pareceu legítimo postular que nas linguagens pluricódicas haveria, pois, uma autonomia das linguagens operantes e uma semiose sincrética entre todos os seus planos (BEIVIDAS, 1987: 19).

$\mathrm{O}$ termo sincretismo pareceu ganhar assim um sentido preciso e um lugar preciso de ocorrência. Como ganho suplementar, seu estatuto de constelação recuperou a etimologia de origem da palavra, a acepção de um "conglomerado heterogêneo" (advém da história da coalizão dos vários povos da ilha de Creta os quais, para sua defesa, deixaram de lado as fortes diferenças de costumes religiosos em prol da causa maior). Por esta etimologia historicamente datada, o termo mantém o sentido de uma certa autonomia de cada um dos participantes. Por sua vez, se por esta acepção etimológica, consegue pôr em evidência a autonomia dos códigos intervenientes, por outra acepção - mais firmada em semiótica, em que uma grandeza (aqui, a linguagem cinematográfica) é capaz de subsumir dois ou mais termos heterogêneos em superposição (aqui, os vários códigos) - consegue-se destacar a 'fusão' estabelecida. ${ }^{7}$ Noutros termos, sincretismo se presta a uma orientação analítica,

\footnotetext{
${ }^{7}$ Olhado à distância de hoje, o estatuto de constelação, isto é, de autonomia dos códigos co-ocorrentes precisaria ser revisto. Frente aos conceitos chamados "indefiníveis" por Hjelmslev (1968, p. 51) - presença, necessidade, condição - a constelação cederia o passo à determinação (função entre constante e variável) no caso de se verificar, por exemplo no cinema, alguma linguagem (código) cuja presença seja constante, necessária, perante outras que não o sejam. Basta pensarmos no cinema mudo para deduzirmos que a linguagem verbal é, no sistema, uma variável. Mas a linguagem visual, imagética, diegética, chamemos como queiramos, de uma câmera, é uma constante.
} 
descritiva - ao preservar a autonomia dos elementos participantes - e, ao mesmo tempo, a uma orientação de síntese, de leitura - assegurando a unicidade global do significado da linguagem manifestante.

\section{3. (In-)conclusões}

Perante os comentários críticos levados a efeito sobre as primeiras definições de sincretismo dos dicionários de semiótica; perante a breve apresentação de nosso próprio estudo sobre o tema; e tendo em consideração que nosso curso ulterior de pesquisa se afastou da temática precisa do sincretismo e do cinema, não temos condições de arrolar conclusões ou apresentar soluções. Aos novos pesquisadores e analistas empíricos, interessados nesse canteiro específico da semiótica, o trabalho de fazer avançar a reflexão. De modo que remetemos o leitor ao conjunto de "tarefas urgentes" que Fiorin $(2009$, p. 39) sugere ao final de seu texto, apenas com o acréscimo de que deva também ser aí incluído o empenho em explorar mais amplamente o conjunto da tipologia das funções hjelmslevianas no sistema e no processo $(1968$, p. 38, 51, 57) - as interdependências (solidariedades no processo, complementaridades no sistema), as determinações (seleção no processo, especificação no sistema), as constelações (combinações no processo, autonomias no sistema). É assim que vemos a chance de ampliar o horizonte de possibilidades descritivas do conceito de sincretismo, mantida a coerência das bases teóricas e ajustadas mais adequadamente às coerções dos objetos sob análise.

\section{REFERÊNCIAS}

BEIVIDAS, W. (1983) Semióticas Sincréticas (O cinema). Posições. 2006, 130 p. [http://www.fflch.usp.br/dl/semiotica/public/beividas_semioticassincreticas.pdf].

"Semióticas Sincréticas" Significação. Revista Brasileira de Semiótica, n. 6, São

Paulo: Centro de Estudos Semióticos, 1987, p. 13-21.

FIORIN, J. L. "Para uma definição das linguagens sincréticas" In: Oliveira, A. C ; Teixeira, L. (Orgs.) Linguagens na Comunicação. Desenvolvimentos da Semiótica Sincrética. São Paulo: Estação das Letras e Cores, 2009, p. 15-40.

FLOCH, J.-M. "Quelques positions pour une sémiotique visuelle" Le Bulletin n. 4-5. Paris: Grsl, 1978, p. 1-16.

"Stragégies de communication syncrétique". Actes Sémiotiques - Bulletin, 27. Paris : Grsl,1983, p. 3-8.

GREIMAS, A. J. Sémantique structurale. Recherche de méthode. Paris: Seuil, 1966,262 p. Du sens - essais sémiotiques. Paris: Seuil, 1970, 318 p.

GREIMAS, A. J. ; COURTÉS, J. Sémiotique. Dictionnaire raisonné de la théorie du langage. Paris : Hachete Université, 1979, 423 p.

Sémiotique. Dictionnaire raisonné de la théorie du langage II. Paris : Hachete Université, 1986, $270 \mathrm{p}$.

HJELMSLEV, L. (1943) Prolégomènes à une théorie du langage. Paris: Minuit, 1968, 235 p.

SAUSSURE, F. Cours de linguistique générale.(Édition critique préparée par Tulio di Mauro). Paris: Payot, 1972, 520 p. 